\title{
Comparison of biocrude oil production from self-settling and non-settling microalgae biomass produced in the Qatari desert environment
}

\author{
P. Das $^{1}$ (D) M. I. Thaher ${ }^{1} \cdot$ S. Khan ${ }^{1} \cdot$ M. AbdulQuadir ${ }^{1}$ A. K. Chaudhary ${ }^{1} \cdot$ G. Alghasal ${ }^{1} \cdot$ H. Al-Jabri ${ }^{1}$
}

Received: 27 December 2018 / Revised: 17 February 2019 / Accepted: 26 March 2019 / Published online: 5 April 2019

(C) The Author(s) 2019

\begin{abstract}
The present study investigated the growth, harvesting, biocrude conversion, and recycling of the HTL aqueous phase for one self-settling (i.e., Chlorocystis sp.) and another non-settling (i.e., Picochlorum sp.) marine microalgae. Both the strains were grown simultaneously in 2 identical 25,000-L raceway ponds in the Qatari desert. The cell size of Picochlorum sp. was small $(2-3 \mu \mathrm{m})$, and its biomass was harvested using a centrifuge. Cells of Chlorocystis sp. $(6-9 \mu \mathrm{m})$ formed flocs that settled spontaneously in a sedimentation chamber. Harvested biomass of these two strains was then converted to biocrude oil, using a 500-mL Parr reactor. The biocrude yield of Picochlorum sp. and Chlorocystis sp. was $39.6 \pm 1.15 \%$ and $34.8 \pm 1.65 \%$, respectively. The energy content of the biocrude oil was 32.78 and $33.38 \mathrm{MJ} / \mathrm{kg}$ for Chlorocystis sp. and Picochlorum sp., respectively. Both the strains were capable of efficiently utilizing more than $95 \%$ nitrogen of the HTL aqueous phase. Although lower biocrude yield was obtained from Chlorocystis sp., compared to Picochlorum sp., harvesting of Chlorocystis sp. would require much lower energy compared to Picochlorum sp. Therefore, a self-settling microalgae (e.g., Chlorocystis sp.) could potentially be a better candidate, over non-settling microalgae, for producing biofuel feedstock.
\end{abstract}

Keywords Large-scale microalgae cultivation · Marine microalgae $\cdot$ Contamination · Hydrothermal liquefaction · Biocrude $\cdot$ Nutrient recycling

\section{Introduction}

Producing liquid fuels from renewable biomass sources is critical to the mitigation of greenhouse gases and ensuring future energy security (Cheng and Timilsina 2011; Bwapwa et al. 2017; Isa et al. 2018). Microalgal biomass represents an attractive feedstock for producing liquid fuel as microalgae can be grown in non-arable land using wastewater, brackish water, and even seawater. Microalgal lipids are the

Editorial responsibility: Shahid Hussain.

Electronic supplementary material The online version of this article (https://doi.org/10.1007/s13762-019-02364-w) contains supplementary material, which is available to authorized users.

P. Das

probir.das@qu.edu.qa

1 Algal Technology Program, Center for Sustainable Development, College of Arts and Sciences, Qatar University, 2713, Doha, Qatar most energy dense molecules compared to carbohydrate and proteins. A few microalgae strains accumulate copious amount of lipid in the stationary phase under nitrogen starvation, and during this time the net biomass productivity is nothing to very low (Singh et al. 2016). Although cellular increase in lipid content, during the stationary phase, will also increase the calorific value of the biomass, the energy demand during this time (e.g., paddle mixing energy in the raceway pond, $\mathrm{CO}_{2}$ supplementation, supplying water to balance the evaporation loss) could cancel out any benefit of lipid enhancement for biofuel application. Although there are multiple techniques of microalgal biomass harvesting available, apart from self-settling technique, all these are either energy intensive or require the addition of chemicals (i.e., organic and inorganic coagulants) (González-Fernández and Ballesteros 2012; Tiron et al. 2017; Das et al. 2018). There are some large-size and colony-forming microalgae, diatom, and cyanobacteria that can be easily separated from the culture by simple sedimentation (i.e., self-settling) or auto-flocculation. 
Currently, hydrothermal liquefaction (HTL) is considered as a promising technique for the conversion of microalgal biomass into biocrude (Han et al. 2019). The HTL technique converts not only the lipid, but also other metabolites (e.g., proteins and carbohydrates) into biocrude oil, although the yield for each metabolite will be different (Biller and Ross 2011). Therefore, biofuel production from a fast-growing and self-settling marine microalgae could provide higher net energy balance compared to a non-settling lipid-rich microalgae. A fraction of the biomass-bound nitrogen and other elements end up in the aqueous phase, a by-product of the HTL process (Gai et al. 2015; Jazrawi et al. 2015); however, the concentration of these elements in the aqueous phase could vary based on the feedstock quality and HTL operating conditions (Patel et al. 2016). Therefore, it is essential to efficiently recycle the nutrients, especially the nitrogen, in the aqueous phase to improve the overall economic viability of the microalgal biofuel (Leng et al. 2018).

Abundant sunlight throughout the year, availability of unutilized desert land, and proximity to the sea render cultivation of marine microalgae/cyanobacteria, in Qatar, very attractive (Das et al. 2015, 2019). The primary objective of this study was to compare the biocrude yield and quality of a self-settling microalga and another non-settling microalgal biomass produced at large scale in the Qatari desert environment. Another objective was to study the aqueous phase nutrient recycling efficiency by these two microalgae.

\section{Materials and methods}

\section{Standards and reagents}

High-performance liquid chromatography (HPLC) grade dichloromethane $(99.8 \% \mathrm{v} / \mathrm{v})$ was purchased from SigmaAldrich, USA. Nitrogen gas ( $99.995 \%$ purity) was obtained from National Industrial Gas Plant. A rack of $16 \mathrm{CO}_{2}$ cylinders (purity $>99.99 \%$ ) was obtained from Buzwair Scientific and Technical Gases. Different HACH kits, i.e., LCK 385 total organic carbon (TOC), LCK 138 total nitrogen (TN), LCK $339\left(\mathrm{NO}_{3}-\mathrm{N}\right)$, LCK $342\left(\mathrm{NO}_{2}-\mathrm{N}\right)$, LCK 305 $\left(\mathrm{NH}_{4}-\mathrm{N}\right)$, LCK 349 Total phosphorous (TP) were purchased form HACH, Germany. Any other chemicals, used in this study, were of either analytical grade or higher purity.

\section{Microalgae strains and the growth medium}

Two indigenous marine strains, Chlorocystis sp. and Picochlorum sp., were used in this experiment. The inoculums of these two cultures, for both indoor and outdoor experiments, were prepared in modified Guillard f/2 medium; urea was used as a source of nitrogen for both these strains, whereas sodium phosphate monobasic was used as a phosphorus source (see supplementary). However, the trace metals were used as per the concentrations of Guillard $f / 2$ recipe. Seawater (43 ppt salinity) was collected from the Dhakhira beach of Al-khor area using 5000-gallon tanker; the collected seawater was initially kept in a 56,000-L fiberglass tank. For cultivating these microalgae, in all cases, natural seawater was first passed through 4.4 C Aquadyne filter and then sterilized using 025150-2 SMART UV sterilizer.

\section{Indoor and outdoor microalgal growth experiment}

Indoor, these two strains were grown in 1-L Duran bottles in a temperature-controlled room, maintained at $25 \pm 1{ }^{\circ} \mathrm{C}$. Compressed air was provided to mix the cultures at a rate $0.5 \mathrm{~L} / \mathrm{min}$. For all the indoor cultivation, white fluorescent lighting (light intensity $600 \mu \mathrm{mol} \mathrm{E} / \mathrm{m}^{2} / \mathrm{s}$ ) was used as $12-\mathrm{h}$ (light)/12-h (dark) photoperiod. The growth rates of these two strains were monitored by taking daily optical density measurement at $750 \mathrm{~nm}$ using a HACH DR3900 spectrophotometer. The calibration curves of optical density (at $750 \mathrm{~nm}$ ) versus total dry solids, for both strains, were previously established (see supplementary). After 10 days of growth, the cultures were centrifuged to separate the biomass and stored inside $-20{ }^{\circ} \mathrm{C}$ fridge until any metabolite analysis. The outdoor growth experiments for these two strains were conducted simultaneously in two identical 25,000-L raceway ponds; details of the raceway ponds were mentioned elsewhere (Das et al. 2015). At first, 1 L culture of each strain was inoculated into a 10-L plastic PBR; a total of 5 similar PBRs were prepared for each strain. All these PBRs were grown indoor using the light conditions mentioned above. Later, the cultures of all these 5 PBRs were transferred in a 1000-L raceway tank. Two such identical raceway tanks were used to prepare the inoculum for the $25,000-\mathrm{L}$ raceway pond. The depth in the ponds was maintained at $20 \mathrm{~cm}$ by adding freshwater, on a daily basis. The linear flow velocity in the ponds was $21-22 \mathrm{~cm} / \mathrm{s}$, under the operating conditions. Bottled $\mathrm{CO}_{2}$ was injected in these cultures at the base of the sump $(35 \mathrm{~cm}$ deeper than the base of the pond) which was regulated by $\mathrm{pH}$ as controlled by YSI probe, controller and software. As the $\mathrm{pH}$ value of the culture reached $8.35, \mathrm{CO}_{2}$ was injected, and it was stopped as the value dropped to 7.85 ; for reference, the $\mathrm{pH}$ value of the collected sweater was 8.1. The outdoor cultures of these strains were regularly checked under the microscope to monitor contamination by undesired microalgal strains. Biomass of these cultures was harvested using either selfsettling (Chlorocystis sp.) or EVODOS Type-25 centrifuge (Picochlorum sp.). The centrifuge was run continuously for an hour (at a rate $2500 \mathrm{~L} / \mathrm{min}$ ), and later the biomass paste was collected from the base tray. On the other hand, 1000-L culture of Chlorocystis sp. was transferred in a settling tank ( $0.3 \mathrm{~m}$ deep, and $5 \mathrm{~m}^{2}$ area) and allowed to settle for $30 \mathrm{~min}$. 
After the biomass settled to the bottom, the top layer was drained off. The bottom layer (approximately $90 \mathrm{~L}$ ) was then collected again in a 100-L container and allowed to settle for another $20 \mathrm{~min}$; after removing another $60 \mathrm{~L}$ supernatant from the top, approximately $30 \mathrm{~L}$ concentrated Chlorocystis sp. sample was obtained. Self-settled Chlorocystis sp. biomass was then concentrated further using $4,400 \mathrm{~mL}$ buckets in a benchtop Thermo-Scientific SL 16R centrifuge. Multiple batches of centrifuge runs were performed to obtain sufficient amount of biomass for the HTL runs. Biomass pastes of these two strains were then sun-dried and kept in a cool place for metabolite analysis and HTL studies.

\section{Characterizing the microalgal metabolites}

First, the cellular protein content in the biomass samples was extracted by $0.5 \mathrm{~N} \mathrm{NaOH}$; next, a colorimetric method was used to quantify the protein content (López et al. 2010). The carbohydrate content in the biomass samples was extracted using a dilute $(5 \% \mathrm{v} / \mathrm{v}) \mathrm{H}_{2} \mathrm{SO}_{4}$ followed by quantification using a modified colorimetric method as described by Albalasmeh et al.(2013). The intracellular lipid content of the biomass samples was extracted using chloroform-methanol solution and was quantified gravimetrically (Folch et al. 1957). Fatty acids fractions of the biomass samples were converted to fatty acid methyl esters (FAME) by one-step transesterification method as described by Lewis et al. (2000); next, the FAMEs were characterized using a Shimadzu 2010 plus GC-FID (Japan). A known amount of biomass was placed in a muffle furnace at $540{ }^{\circ} \mathrm{C}$ for $4 \mathrm{~h}$; the remaining inorganic fraction was quantified and used to calculate the ash content. The more details of these analytical procedures were provided before (Das et al. 2016).

\section{HTL experimentation}

The HTL conversion of biomass samples to bio-oil was carried out in a 500-mL Parr reactor (Parr Instruments Co., IL, USA). The reactor was loaded with $45 \mathrm{~g}$ of dry microalgal biomass and $255 \mathrm{~mL}$ of deionized water. Next, the reactor was closed and purged 3 times with nitrogen gas to remove any residual oxygen gas. After purging with nitrogen, the reactor was pressurized to 10 bar with nitrogen gas. The reactor was heated at a rate of $14{ }^{\circ} \mathrm{C} / \mathrm{min}$ until it reached $325^{\circ} \mathrm{C}$ (the pressure reached 190 bar); the temperature of the reactor was maintained at $325{ }^{\circ} \mathrm{C}$ for $30 \mathrm{~min}$ for the completion of the reaction. The content of the reactor was mixed at a constant speed of $150 \mathrm{rpm}$ using a mechanical stirrer controlled using Parr 4848 controller. After completion of the reaction, the reactor was quickly cooled down to ambient temperature by separating reactor from heating mantle and circulating cold water through internal cooling coils present inside the reactor.
Next, the gases from the reactor were vented to atmosphere through a gas outlet port followed by the addition of $150 \mathrm{~mL}$ dichloromethane (DCM) inside the reactor; the reactants were mixed with DCM for $5 \mathrm{~min}$. The reaction mixture was then poured into a $1 \mathrm{~L}$ separating funnel. After 30 min of phase separation, the upper layer of the aqueous phase and the bottom layer of the organic phase containing biocrude were separated and centrifuged. The solid mass obtained after centrifugation was oven dried at $80{ }^{\circ} \mathrm{C}$ overnight to obtain the biochar. The DCM layer was vaporized at $50{ }^{\circ} \mathrm{C}$ to determine the biocrude yield.

\section{Determination of heating value}

The energy densities of the raw biomass feedstock and the crude oil samples were determined by calculating the higher heating value (HHV) of these samples. Dulong's empirical formula was used to calculate the HHV (He et al. 2018). Elemental composition (C, H, N, and $\mathrm{O}$ ) of all these samples was determined by a Flash $2000 \mathrm{CHN}$ analyzer from ThermoFisher scientific. S content in the samples was determined separately. Initially, a known amount of sample was digested in a $100-\mathrm{mL}$ mini high-pressure bomb-type reactor using concentrated $\mathrm{HNO}_{3}$ in a muffle furnace at $140{ }^{\circ} \mathrm{C}$; the digested sample was then filtered using $0.45-\mu \mathrm{m}$ syringe filter, and the concentration of sulfur in this sample was determined by an Agilent 7700 series Inductively coupled plasma-mass spectroscopy (ICP-MS) machine. Dulong's empirical (Eq. 1) was used for calculating HHV.

Higher heating value $(\mathrm{MJ} / \mathrm{kg})=0.338 \mathrm{C}+1.428(\mathrm{H}-\mathrm{O} / 8)+0.095 \mathrm{~S}$

\section{Characterization of bio-oil}

To characterize the organic compounds in the biocrude oil sample, it was analyzed with a 7890A Agilent Technologies GC system connected to a 5973 Network mass selective detector; organic compounds in the biocrude oil were identified using NIST98 mass spectral library database. Sodium sulfate anhydrous was added to the biocrude containing DCM layer to remove any moisture. Next, the supernatant was passed through a syringe filter $(0.45 \mu \mathrm{m})$, and the sample was then kept at $4{ }^{\circ} \mathrm{C}$ until GC analysis. The sample $(1 \mu \mathrm{L}$ in splitless mode) was injected to a $30 \mathrm{~m} \times 250 \mu \mathrm{m} \times 0.25 \mu \mathrm{m}$ Rxi-5Sil MS column, while the injector temperature was kept constant at $300{ }^{\circ} \mathrm{C}$. The pressure inside the column was maintained at 15 psi. Helium gas was used, as a carrier, at a flowrate of $1.677 \mathrm{~mL} / \mathrm{min}$. After injecting the sample, the oven temperature was kept at $60^{\circ} \mathrm{C}$ for 2 min which was then increased to $300{ }^{\circ} \mathrm{C}$ at $6{ }^{\circ} \mathrm{C} / \mathrm{min}$ followed by a 20 -min hold at $300{ }^{\circ} \mathrm{C}$. An ion source was used for the mass spectrometer used which was operated in MS-scan mode. 


\section{Characterization of the aqueous phase}

After separating the DCM-soluble biocrude fraction from the HTL products mix, the remaining mixer was centrifuged again to separate the solid content. The supernatant, also known as the aqueous phase (AP), was then collected in another container. The $\mathrm{pH}$ and salinity of the aqueous phase liquid (or, APL) were recorded immediately Ohaus ST20 digital handheld pH meter and Omega RFH211ATC refractometer, respectively. The AP was filtered using a WHATMAN $0.7 \mu \mathrm{m} \mathrm{GF/F} \mathrm{filter} \mathrm{and} \mathrm{diluted} 1000$ times for the analysis. The concentrations of total organic carbon, total nitrogen, nitrate, nitrite, ammonium, and total phosphorus in the AP were determined by respective $\mathrm{HACH}$ kits and a HACH DR3900 spectrophotometer.

\section{Recycling the nutrients of aqueous phase}

Nutrient recycling from AP was studied indoor in 1-L photobioreactors (PBRs). In one set of PBRs, all the nutrients were added as half of the concentrations (see "Microalgae strains and the growth medium" section), and later a specific volume of AP was added to the culture such that the initial nitrogen concentration was doubled. In another set of PBRs (control experiment), $42 \mathrm{mg} \mathrm{N} / \mathrm{L}$ of growth media was prepared at the beginning by adding urea. A $5 \%$ inoculum was used for the growth study to minimize the effect of residual nitrogen from the inoculum. The growth conditions were the same as described in "Microalgae strains and the growth medium" section. For the nutrient recycling study, by these two strains, the APs obtained from the biomass of respective strains were used.

\section{Statistical analysis}

Apart from the outdoor large-scale microalgal cultivation, all growth experiments were conducted in triplicates. Average values of three independent samples were reported together with standard error. The significant difference between the means of independent treatments was statistically determined using one-way ANOVA; an $\alpha$ value of 0.05 was considered for the analysis.

\section{Results and discussion}

\section{Growth comparison of the strains}

In the indoor experiment, biomass yield of Picochlorum sp. $(0.82 \pm 0.013 \mathrm{~g} / \mathrm{L})$ was significantly higher as compared to the biomass yield of Chlorocystis sp. $(0.76 \pm 0.01 \mathrm{~g} / \mathrm{L})$ $(p<0.05)$; similarly, the specific growth rate (based on the $\log$ phase growth) of Picochlorum sp. $\left(0.39 \pm 0.015 \mathrm{~d}^{-1}\right)$ was significantly different than that of Chlorocystis sp. $\left(0.34 \pm 0.003 \mathrm{~d}^{-1}\right)(p<0.05)$. The cultivation and growth profile of Picochlorum sp. and Chlorocystis sp. in outdoor 25,000-L raceway ponds are compared in Figs. 1 and 2b, respectively. Similar to indoor experiment, Picochlorum sp. had higher growth rate compared to Chlorocystis sp. However, an unidentified floc-forming cyanobacterium (possibly an Anabaena sp.; see supplementary) was first spotted on day 6 and its number was increasing (as seen by microscopic observation) till 8th day of cultivation; therefore, the growth of Picochlorum sp. was not continued after day 8. During the harvesting time, the biomass densities of Picochlorum sp. and Chlorocystis sp. were $0.582 \pm 0.007$ and $0.561 \pm 0.014 \mathrm{~g} / \mathrm{L}$, respectively; therefore, the average areal biomass productivities were 14.6 and $11.2 \mathrm{~g} / \mathrm{m}^{2} / \mathrm{d}$ for Picochlorum sp. and Chlorocystis sp., respectively. Although very high sunlight intensity (as high as $2256 \mu \mathrm{mol} \mathrm{E} / \mathrm{m}^{2} / \mathrm{s}$ ) was available for the outdoor cultivation as compared to the indoor growth experiment $\left(600 \mu \mathrm{mol} \mathrm{E} / \mathrm{m}^{2} / \mathrm{s}\right)$, the total dry solids of both strains in the outdoor raceway pond cultures were significantly lower compared to the total dry solids of indoor cultures $(p<0.05)$. The optical path of the PBRs was $8.96 \mathrm{~cm}$, whereas the culture depth of the ponds was $20 \mathrm{~cm}$; hence, light could have become limiting in the raceway pond (Chisti 2016). Furthermore, the mixing in the PBRs was superior to the mixing in the raceway ponds which allowed better light penetration in the PBR cultures compared to raceway pond cultures (Melis 2009).
Fig. 1 Pictures of Picochlorum sp. (left) and Chlorocystis sp. (right) cultures in outdoor $25,000-\mathrm{L}$ raceway ponds on 6 th day of cultivation

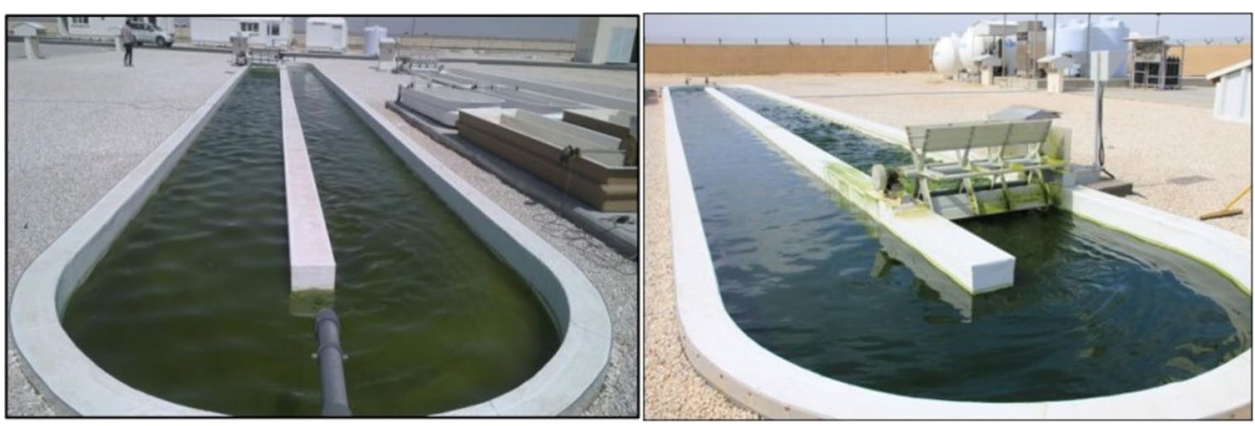


Fig. 2 Growth profiles of Picochlorum sp. and Chlorocystis sp. a indoor 1-L PBRs $(n=3)$, b outdoor $25,000-\mathrm{L}$ raceway ponds

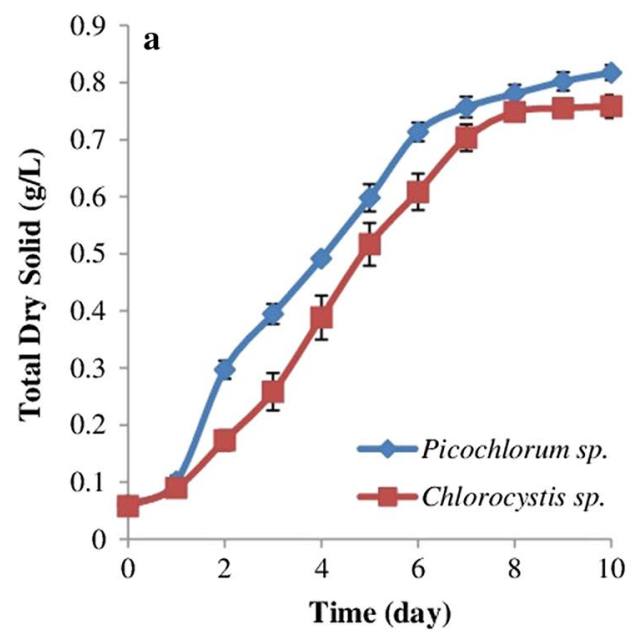

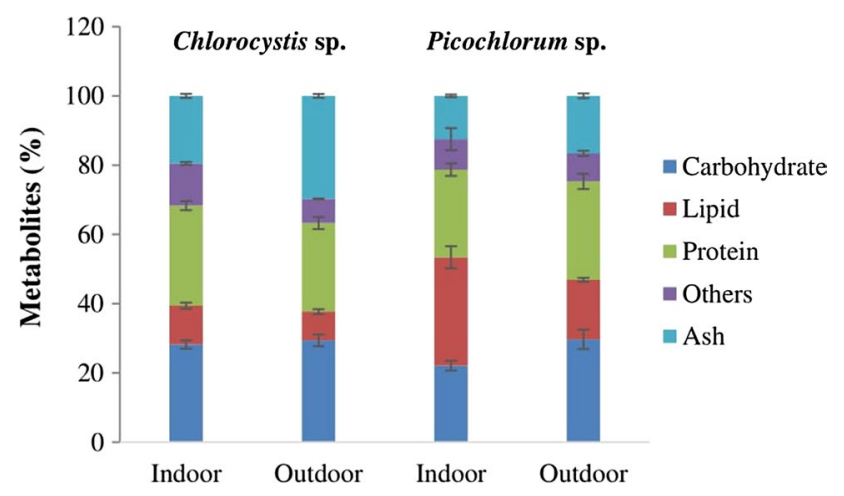

Fig. 3 Comparison of metabolites for both indoor- and outdoorgrown Chlorocystis sp. and Picochlorum sp. $(n=3)$

\section{Comparison of the metabolites}

For both indoor and outdoor trials, Picochlorum sp. had higher lipid content compared to Chlorocystis sp. (Fig. 2). The difference in lipid contents between indoor- and outdoor-grown Picochlorum sp. biomass was very high (Fig. 3). In the indoor growth trial, Picochlorum sp. culture was in stationary phase for 4 days, whereas the outdoor culture was contaminated before reaching the stationary phase. Additionally, the invading cyanobacteria possibly could have very low lipid and the mixed biomass, therefore, had low lipid content. Similarly, outdoor-grown Picochlorum sp. biomass had higher carbohydrate and protein content compared to indoor-grown Picochlorum sp. biomass. For the indoor cultures, ash content was higher in Chlorocystis sp. biomass compared to Picochlorum sp. biomass; sedimentation of Chlorocystis sp. cells could also be linked with high cellular ash content (Matsumoto et al. 2000; Yuan et al. 2016). However, the ash content in both species was much higher in the outdoor cultures, compared to the indoor cultures. Harvested microalgal biomass could have air-borne

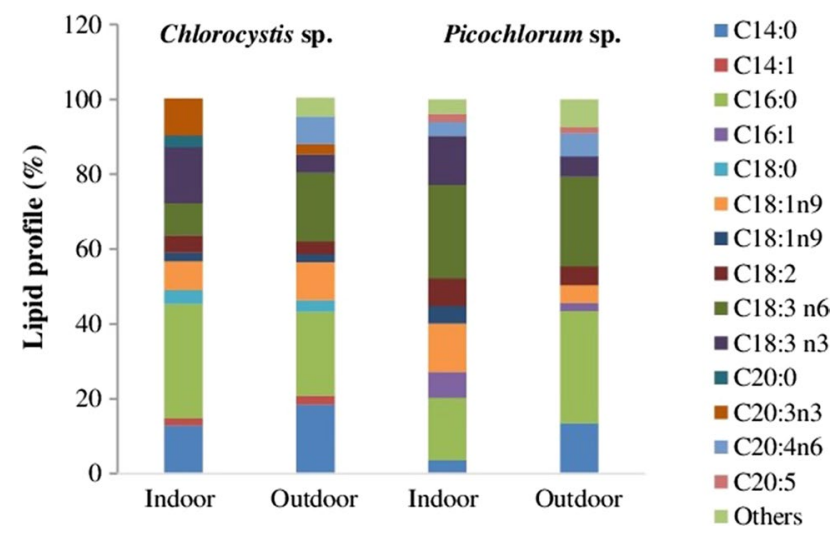

Fig. 4 Lipid profile of indoor- and outdoor-grown Chlorocystis sp. and Picochlorum sp. biomass $(n=3)$

sand and dust particles which were carried by wind, and this could have increased the ash content in the outdoor-grown biomass. Despite continuous paddle mixing, Chlorocystis sp. biomass used to settle at the bottom of the pond. Settled biomass was occasionally brought to suspension by a plastic wiper which could have also brought the settled particle in the suspension, thereby increasing the ash content in the Chlorocystis sp. biomass. Lipid profiles of indoorand outdoor-grown biomass varied for both Chlorocystis sp. and Picochlorum sp. (Fig. 4). Different light intensity and temperature for the indoor and outdoor cultures could have been the major reasons for the variation in lipid profiles. In addition to these factors, outdoor culture of Picochlorum sp. was contaminated by another cyanobacterium and hence outdoor-grown biomass had a much different lipid profile than indoor-grown biomass lipid profile. Myristic acid, palmitic acid and $\mathrm{Y}$-Linolenic acid were the major fatty acids comprising 59.4 and $67.5 \%$ of total fatty acids for outdoor-grown Chlorocystis sp. and Picochlorum sp. biomass, respectively. 


\section{HTL product yields}

The properties of the biomass feedstock are listed in Table 1 . The HHVs of the biomass were 13.87 and $17.4 \mathrm{MJ} / \mathrm{kg}$ for Chlorocystis sp. and Picochlorum sp., respectively; however, the HHV of the ash-free dry biomass was 19.59 and $20.7 \mathrm{MJ} / \mathrm{kg}$ for Chlorocystis sp. and Picochlorum sp., respectively. HTL products distribution for the two microalgal feedstocks and the properties of the biocrude samples are listed in Tables 1 and 2, respectively. The biocrude yield (on an ash-free dry weight basis) from Chlorocystis sp. and Picochlorum sp. biomass was 35.8 and $39.6 \%$, respectively; the HHVs of the biocrude samples were 32.8 and $33.4 \mathrm{MJ} / \mathrm{kg}$ for Chlorocystis sp. and Picochlorum sp., respectively. The biocrude yield from Picochlorum sp. was 3.8\% higher compared to that of Chlorocystis sp. which could be attributed to the higher lipid content in Picochlorum sp. as compared to Chlorocystis sp. (Thao et al. 2017). The solid biochar yields were 18.03 and 12.15 for Chlorocystis sp. and Picochlorum sp., respectively. As a by-product of the HTL process, some

Table 1 Properties of biomass feedstock for the HTL experiment $(n=3)$

\begin{tabular}{lrc}
\hline Microalgae sample & Chlorocystis $\mathrm{sp}$. & Picochlorum $\mathrm{sp}$. \\
\hline Carbon (\%) & $32.33 \pm 2.62$ & $44.02 \pm 1.81$ \\
Nitrogen (\%) & $3.41 \pm 0.24$ & $2.90 \pm 0.14$ \\
Hydrogen (\%) & $5.67 \pm 0.48$ & $5.63 \pm 0.28$ \\
Oxygen (\%) & $28.79 \pm 1.89$ & $30.87 \pm 1.35$ \\
Ash content & $29.8 \pm 0.46$ & $16.6 \pm 1.37$ \\
High heating value $(\mathrm{MJ} / \mathrm{kg})^{\mathrm{a}}$ & $13.87 \pm 0.27$ & $17.41 \pm 0.54$ \\
High heating value $(\mathrm{MJ} / \mathrm{kg})^{\mathrm{b}}$ & $19.59 \pm 0.32$ & $20.7 \pm 0.73$ \\
O/C ratio & $0.66 \pm 0.05$ & $0.53 \pm 0.02$ \\
$\mathrm{H} / \mathrm{C}$ ratio & $2.1 \pm 0.13$ & $1.53 \pm 0.02$ \\
\hline
\end{tabular}

${ }^{\mathrm{a}}$ With ash

${ }^{\mathrm{b}}$ Without ash gases are formed; the higher the temperature, the higher percentage of gas is produced. It was reported that $\mathrm{CO}_{2}$ had the major fraction in the gaseous by-products, while $\mathrm{H}_{2}, \mathrm{CO}$, and $\mathrm{CH}_{4}$ were present in very low concentration (Faeth et al. 2016; Han et al. 2019). If the HTL reactions are conducted at critical temperatures (i.e., $375^{\circ} \mathrm{C}$ ) or above, then $\mathrm{CO}_{2}$ in gas phase could decline and small hydrocarbon-like $\left(\mathrm{CH}_{4}\right.$ and $\mathrm{C}_{2}-\mathrm{C}_{3}$ ) gases could be formed (López Barreiro et al. 2013; Han et al. 2019).

Although the obtained biocrude yields from these two microalgal biomass were lower than the biocrude yields from some other microalgal biomass (Minowa et al. 1995; Brown et al. 2010; López Barreiro et al. 2013), to determine the optimum biocrude yield from these two microalgal biomass different HTL parameters (e.g., temperature, duration, catalyst) need to be studied in detail. Nevertheless, the calorific values of the biocrudes were much higher than those of the original raw biomass and roughly $30 \%$ lower than the value of petroleum crude. $\mathrm{O} / \mathrm{C}$ ratio of biocrudes was lower than their corresponding biomass indicating an increase in carbon content and a reduction in oxygen content. On the other hand, $\mathrm{O} / \mathrm{C}$ ratios of biocrude oils were higher compared to that of petroleum crude oil. However, $\mathrm{H} / \mathrm{C}$ ratio of biocrudes was closer to the specified limits as found in petroleum crude oil (Table 2). Apart from elemental $\mathrm{O}$, the biocrude oil samples had higher concentrations of the elemental N (>4\%) compared to petroleum crude oil. Therefore, removal of these heteroatoms from the crude oils would be essential for making them suitable either for blending feedstock with existing refinery petrocrude or for direct production of transportation fuels. Biocrude obtained through HTL could be upgraded using homogenous or heterogenous catalyst to remove the heteroatoms and improve the quality of the crude oil (Ross et al. 2010; Duan and Savage 2011). For catalytic hydrotreating process, biocrude is usually treated with hydrogen gas in the presence of an appropriate catalyst (e.g., NiMo, CoMo) at elevated temperatures (e.g.,
Table 2 HTL product and elemental distributions of Chlorocystis sp. and Picochlorum sp.

\begin{tabular}{llll}
\hline & Chlorocystis sp. & Picochlorum sp. & Petroleum crude oil \\
\hline Biocrude yield (\%) & $34.8 \pm 1.5$ & $39.6 \pm 1.15$ & \\
Biochar yield (\%) & $18.03 \pm 1.4$ & $12.15 \pm 1.15$ & \\
Gases and losses yield (\%) & $47.17 \pm 2.9$ & $48.25 \pm 2.3$ & \\
C content in crude (\%) & $72.4 \pm 1.1$ & $73.6 \pm 1.3$ & $81-89$ \\
N content in crude (\%) & $7.74 \pm 0.78$ & $7.69 \pm 0.27$ & 0.3 \\
H content in crude (\%) & $4.05 \pm 0.17$ & $4.41 \pm 0.21$ & $9-13$ \\
O content in crude (\%) & $15.51 \pm 0.31$ & $14.02 \pm 0.57$ & 0.7 \\
Ash content in crude (\%) & $0.11 \pm 0.02$ & $0.18 \pm 0.02$ & $0.5-6$ \\
High heating value (MJ/kg) & $32.8 \pm 0.69$ & $33.4 \pm 0.16$ & $39-43.5$ \\
O/C ratio & $0.16 \pm 0.005$ & $0.14 \pm 0.008$ & 0.01 \\
H/C ratio & $1.28 \pm 0.15$ & $1.25 \pm 0.07$ & $1.2-1.8$ \\
Reference & This study & This study & Speight (1999) \\
\hline
\end{tabular}


$405^{\circ} \mathrm{C}$ ) (Biller et al. 2015). Reduction of these heteroatoms could improve the calorific value of the biocrude.

\section{Biocrude chemical composition}

Gas chromatography-mass spectrometry (GC-MS) analyses of the biocrude samples revealed that different alkanes, alkenes and polyaromatic hydrocarbons were present in both the biocrude samples. The biocrude samples of Chlorocystis sp. and Picochlorum sp. had 18 and 24 alkanes, respectively; these alkanes were in the range of $\mathrm{C}_{8}-\mathrm{C}_{20}$ (Fig. 5a). Other than alkanes, 22 additional components were identified in the biocrude sample of Chlorocystis sp. that contained most alkenes and polyaromatic hydrocarbons (Fig. 5b); alkenes were in the range of $\mathrm{C}_{8}-\mathrm{C}_{11}$ hydrocarbons, and other compounds were phenol, thiazole, tetrahydropyridol, benzoic acid. Two fatty acids (i.e., hexadecanoic acid, decanedioic acid) were also identified in the biocrude of Chlorocystis sp. Eleven products, other than alkanes, were identified from biocrude sample of Picochlorum sp. (Fig. 5b); the compounds were alkenes (octaene, undecene, benzene), polyaromatic derivatives (heptanoates, ethenone) and other products (decanedioic acid, phosphonic acid, benzoic acid).
Majority of alkanes ( $\mathrm{Li}$ et al. 2014) formed in the biocrudes were in the range of $\mathrm{C}_{8}-\mathrm{C}_{19}$ hydrocarbons; hence, based on the distribution these hydrocarbons, the produced biocrude samples had the potential to be used as transportation fuel after conducting hydrotreatment, i.e., hydrodeoxygenation and hydrodenitrogenation (Venkatakrishnan et al. 2014). Upgrading via hydrotreatment will not only remove heteroatoms but will also improve calorific value, thereby enhancing the potential of utilizing the bio-oil as transportation fuel (Zacher et al. 2014).

\section{The potential recycling of the aqueous phase liquid (APL)}

The physiochemical properties of APLs, obtained from HTL of Picochlorum sp. and Chlorocystis sp. biomass, are shown in Table 3. The APL of Chlorocystis sp. (C-APL) had higher TN content as compared to the APL of Picochlorum sp. (P-APL) which could be explained by the higher cellular nitrogen content in Chlorocystis sp. compared to Picochlorum sp. The combined concentration of nitrate and nitrite, in both APL samples, was lower than $0.5 \mathrm{mg} / \mathrm{L}$; the concentration of ammonium- $\mathrm{N}$ was
Fig. 5 a Distribution of alkanes in the biocrude samples obtained from Chlorocystis sp. and Picochlorum sp. b Distribution of alkenes, polyaromatics and others in the biocrude samples obtained from Chlorocystis sp. and Picochlorum sp
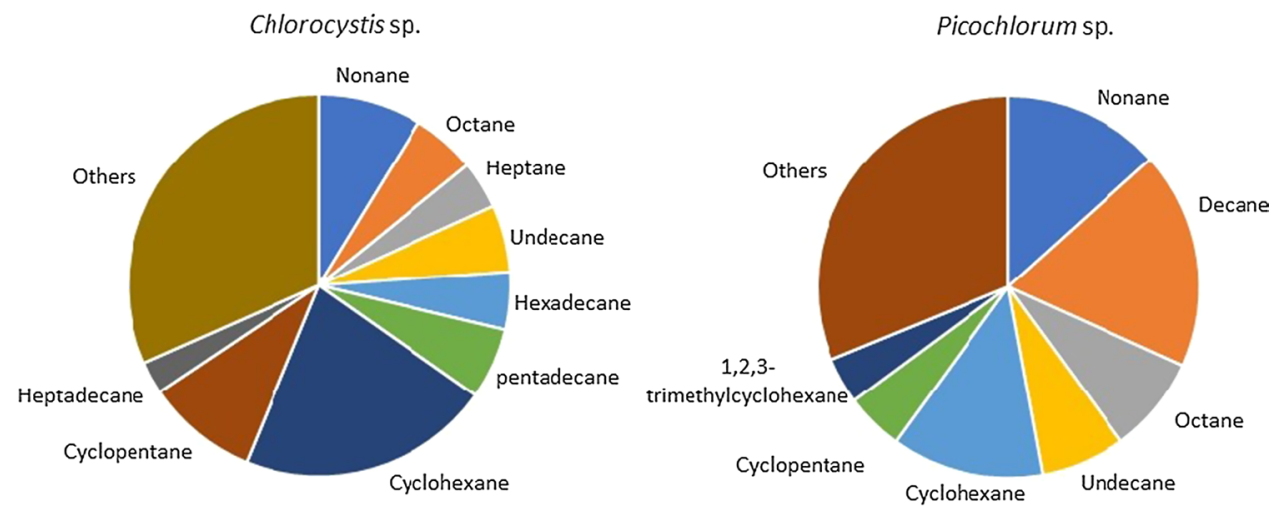

a Distribution of alkanes in the biocrude samples obtained from Chlorocystis sp. and Picochlorum sp.
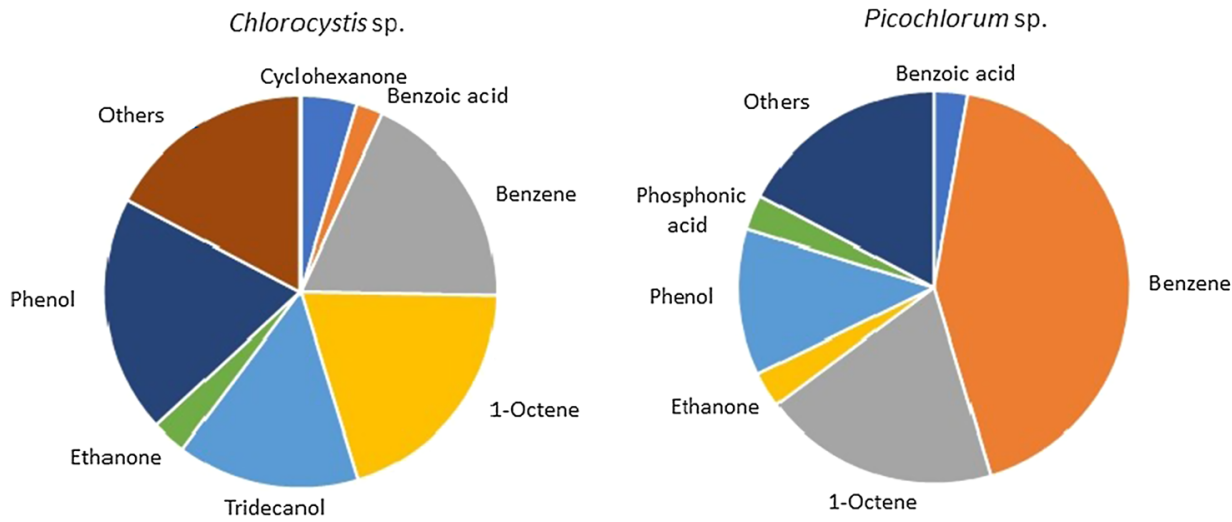

b Distribution of alkenes, polyaromatics and others in the biocrude samples obtained from Chlorocystis sp. and Picochlorum sp. 
Table 3 Characteristics of the aqueous phase liquids $(n=3)$

\begin{tabular}{lllllc}
\hline Microalgae strain & $\mathrm{pH}$ & $\mathrm{TN}(\mathrm{mg} / \mathrm{L})$ & $\mathrm{TP}(\mathrm{mg} / \mathrm{L})$ & $\mathrm{TOC}(\mathrm{mg} / \mathrm{L})$ & Salinity $(\mathrm{ppt})$ \\
\hline Picochlorum sp. & $8.10 \pm 0.04$ & $2520 \pm 79$ & $692 \pm 18$ & $12,406 \pm 217$ & $46.1 \pm 2.2$ \\
Chlorocystis sp. & $7.79 \pm 0.07$ & $3841 \pm 113$ & $743 \pm 31$ & $13,914 \pm 366$ & $36.3 \pm 1.6$ \\
\hline
\end{tabular}

538 and $765 \mathrm{mg} / \mathrm{L}$ for Picochlorum sp. and Chlorocystis sp. APLs, respectively. Both wet biomasses were dried under the sun, and hence the dried biomasses were having seasalt. Moisture content in the Picochlorum sp. biomass (79\%) was higher than in Chlorocystis sp. (72\%). This led to higher salinity value of the P-APL compared to that of C-APL. From the microalgal feedstock, typically, 20\% of organic carbon ends up in the APL (Leng et al. 2018). Similarly, loss of organic carbon in the P-APL and C-APL was 18 and 24\%, respectively. During the HTL process, protein hydrolysis and deamination form ammonium and therefore the $\mathrm{pH}$ value of APL would be high if the biomass has high protein content (Patel et al. 2016). Since Picochlorum sp. biomass had more protein than Chlorocystis sp. biomass, the APL of Picochlorum sp. had higher $\mathrm{pH}$ value compared to that of Chlorocystis sp.

Since the APLs were added just to provide half of the nitrogen requirement, the concentration of organics in the cultures was also very low; therefore, the concentrations of possible toxic compounds, if any, in the cultures were low. Both the Chlorocystis sp. and the Picochlorum sp. were able to utilize the nitrogen and phosphorus from the APL liquid; however, the biomass growth rate and biomass yield were lower compared to control cultures (Fig. 6). At the end of the growth in the control cultures, residual $\mathrm{TN}$ values were 0.36 and $0.68 \mathrm{mg} / \mathrm{L}$ for Picochlorum sp. and Chlorocystis sp., respectively. The concentrations of residual $\mathrm{TN}$ values were 0.74 and $1.14 \mathrm{mg} / \mathrm{L}$ in APL spiked cultures of Picochlorum sp. and Chlorocystis sp., respectively. Typically, ammonium- $\mathrm{N}$ is more bioavailable than other common forms of nitrogen (i.e., nitrate, organic nitrogen, etc.) to the microalgae $(\mathrm{Hu}$ et al. 2017). In addition, some microalgae are capable of selectively consuming the amino substituents of multiple cyclic organic compounds (López Barreiro et al. 2015). Overall, the utilization efficiencies of APL nitrogen were, at least, 94.7 and $91.8 \%$ in Picochlorum sp. and Chlorocystis sp. cultures, respectively. Carbon dioxide was not provided during the cultivation of these two strains, and hence the $\mathrm{pH}$ values of the cultures were increasing (data not shown here); final $\mathrm{pH}$ values of the cultures were 9.6 and 9.4 for Picochlorum sp. and Chlorocystis sp. cultures, respectively. Therefore, it was possible that a small fraction of the nitrogen was lost from these cultures as free ammonia due to the increase in $\mathrm{pH}$ value (Patel et al. 2016).

\section{Selection of suitable strains}

Harvesting of microalgal biomass is a major obstacle in producing biomass feedstock for low value products like biocrude oil (Uduman et al. 2010; Sharma et al. 2014). Picochlorum sp. had much smaller cell size $(2-3 \mu \mathrm{m})$ compared to Chlorocystis sp. $(6-9 \mu \mathrm{m})$. Since Chlorocystis sp. used to settle spontaneously, no other harvesting method was studied for this strain. However, for Picochlorum sp., the harvesting efficiency of different techniques (coagulation-flocculation, $\mathrm{pH}$ adjustment, electrocoagulation) didn't exceed $70 \%$ (data not provided here); therefore, EVODOS centrifuge was used to harvest the pond culture at a rate $3000 \mathrm{~L}$ per hour. Later, a cross-flow unit was developed that could process 2000 L Picochlorum sp.
Fig. 6 Growth comparisons of the strains in control and APL supplemented cultures in 1-L PBRs $(n=3)$ : Chlorocystis sp. (left), Picochlorum sp. (right)
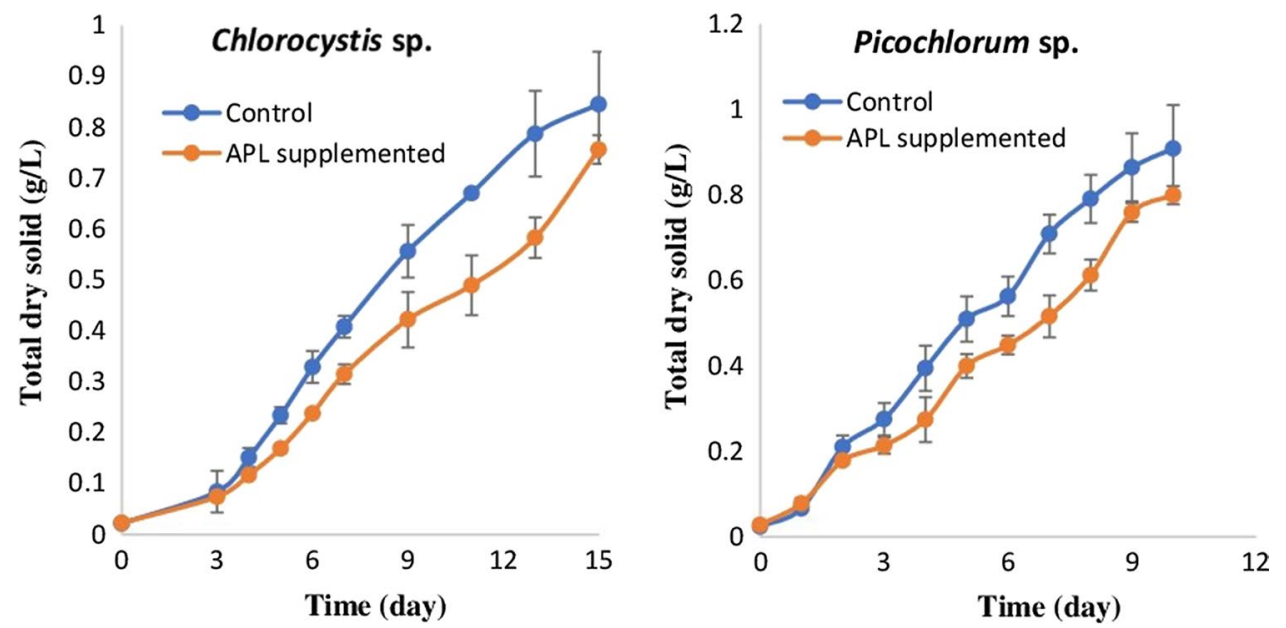
culture in $1 \mathrm{~h}$ (data not shown); the energy consumption for the cross-flow unit alone was estimated as $5.5 \mathrm{MJ} / \mathrm{kg}$ biomass, whereas the energy consumption of EVODOS centrifuge was $8.97 \mathrm{MJ} / \mathrm{kg}$. Additionally, self-settling or bioflocculating microalgae would make biomass harvesting very simplistic (Das et al. 2018). A comparison of energy consumption in biomass harvesting and HTL processing, for both of these strains, is shown in Fig. 7 (details are provided in the supplementary). The energy requirement for pumping Chlorocystis sp. and Picochlorum sp. was 0.07 and $0.068 \mathrm{MJ} / \mathrm{kg}$, respectively. The energy consumption by the centrifuge to process the settled biomass slurry of Chlorocystis sp. was $0.26 \mathrm{MJ} / \mathrm{kg}$. Since Picochlorum sp. whole culture was centrifuged, its energy consumption (i.e., $8.97 \mathrm{MJ} / \mathrm{kg}$ ) was much higher. In an alternative approach, a cross-flow unit was used to concentrate the Picochlorum sp. culture to $4 \%$ solid content which was then centrifuged to a $20 \%$ solid content; the total harvesting energy consumption for the alternative approach was $5.63 \mathrm{MJ} / \mathrm{kg}$. In all cases, the HTL process consumed $4.09 \mathrm{MJ} / \mathrm{kg}$ energy, assuming a $50 \%$ recovery of heat. Therefore, the energy consumption of biomass harvesting and HTL process was 4.38 and $9.71 \mathrm{MJ} / \mathrm{kg}$ for Chlorocystis sp. and Picochlorum sp. (improved scenario), respectively. The caloric value of the produced biocrude oils was 11.41 and 13.22 MJ for Chlorocystis sp. and Picochlorum sp., respectively. Therefore, the energy balance of biocrude production could be better for Chlorocystis sp. (EROI =2.58) compared to Picochlorum sp.
$(\mathrm{EROI}=1.36)$ - primarily due to the low energy requirement in harvesting.

Microalgal biomass conversion to biocrude oil was reported to be as high as 60\% (López Barreiro et al. 2013); the yield and quality of the biocrude would vary based on the metabolite content, use of catalyst, and the HTL operating conditions. Among the three major metabolites, lipid conversion to biocrude oil is maximum, while for carbohydrate it is the least. Both the biomass samples in this study had the lowest lipid and the highest carbohydrate content which could be the reason of lower biocrude yields for these biomass samples. Furthermore, no catalyst was used during the HTL process. Nevertheless, apart from a small difference in biocrude yield, the calorific value, elemental and molecular composition of the biocrudes were almost similar for Chlorocystis sp. and Picochlorum sp. Since AP has very low calorific value, any attempt to recover a fraction of it would not be favorable. Nitrogen and phosphorus content in the microalgal biomass can vary from 2 to $10 \%$ and 0.2 to $0.5 \%$, respectively, which depend on the strain, nutrients addition, culture condition, etc. Considering the high energy requirement to manufacture fertilizers of nitrogen and phosphorus (Helsel 1992; Peccia et al. 2013), it is very crucial to recycle the nitrogen and phosphorus since the concentration of these elements in the final product (i.e., bio-oil) should be as low as possible. Generally, APL contains more than $50 \%$ of the biomass-bound nitrogen as cyclic nitrogen compounds and ammonia. In this study, the APLs of Picochlorum sp. and Chlorocystis sp. biomass had $49 \%$ and $64 \%$ of the biomass-bound nitrogen,

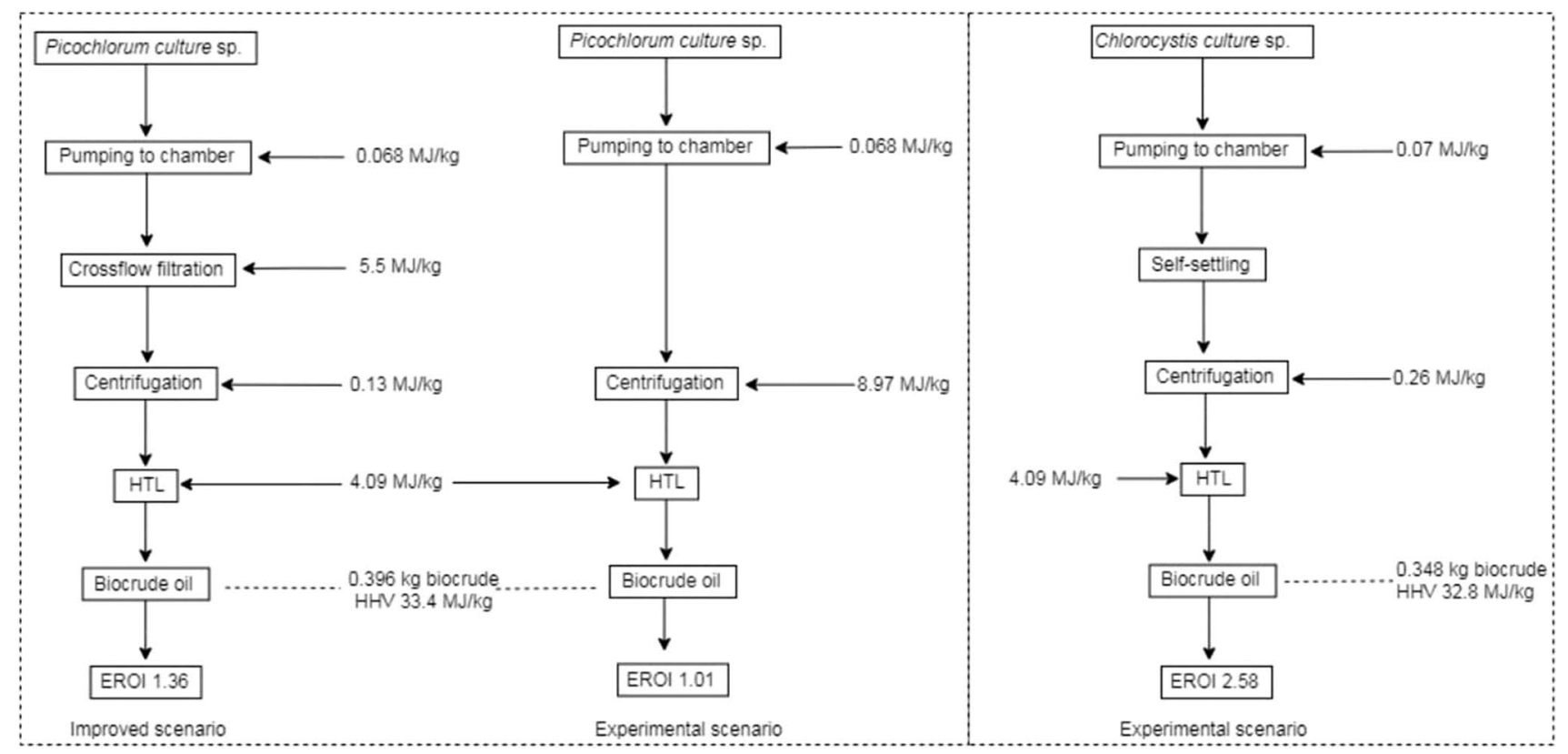

Fig. 7 Schematic of energy consumption in biocrude production process for Picochlorum sp. and Chlorocystis sp 
respectively. Despite higher biomass productivity of Picochlorum sp. and slightly higher biocrude yield from its biomass, Chlorocystis sp. still offers more favorable cost and energy balance for biofuel application because of the energy saving in biomass harvesting. Similar to Chlorocystis sp., other fast-growing and self-settling microalgae and cyanobacteria could be considered as potential feedstock for biofuel.

\section{Conclusion}

The potential of making biocrude oil from a non-settling (i.e., Picochlorum sp.) and a self-settling (i.e., Chlorocystis sp.) marine microalgal biomass, grown in the Qatari desert, was explored in this study. The characteristics of the biocrude oil from these two microalgal biomass samples were almost similar although the biocrude yield from Picochlorum sp. was little higher (4.8\%) than that of Chlorocystis $\mathrm{sp}$. Furthermore, both the strains were very efficient to recycle the nitrogen from the HTL aqueous phase liquid. However, the energy requirement of harvesting alone of a non-settling microalga, like Picochlorum sp., could not only diminish the additional yield of biocrude but also undermine the overall energy balance of biofuel production. Hence, fast-growing microalgal strains exhibiting self-settling phenomenon (e.g., Chlorocystis sp.) could be a potential feedstock for biofuel.

Acknowledgements Open Access funding provided by the Qatar National Library. The authors would like to acknowledge the support of Qatar National Research Fund (QNRF, a member of Qatar Foundation) for providing the funding (under Grant NPRP8-646-2-272) for this study. The authors appreciate the assistance of Ms. Noora (from ESE labs) and Dr. Ahmed (from CLU) for GC-MS and CHN analyses, respectively.

Open Access This article is distributed under the terms of the Creative Commons Attribution 4.0 International License (http://creativeco mmons.org/licenses/by/4.0/), which permits unrestricted use, distribution, and reproduction in any medium, provided you give appropriate credit to the original author(s) and the source, provide a link to the Creative Commons license, and indicate if changes were made.

\section{References}

Albalasmeh AA, Berhe AA, Ghezzehei TA (2013) A new method for rapid determination of carbohydrate and total carbon concentrations using UV spectrophotometry. Carbohydr Polym 97:253-261. https://doi.org/10.1016/j.carbpol.2013.04.072

Biller P, Ross AB (2011) Potential yields and properties of oil from the hydrothermal liquefaction of microalgae with different biochemical content. Bioresour Technol 102:215-225. https://doi. org/10.1016/j.biortech.2010.06.028

Biller P, Sharma BK, Kunwar B, Ross AB (2015) Hydroprocessing of bio-crude from continuous hydrothermal liquefaction of microalgae. Fuel 159:197-205. https://doi.org/10.1016/j. fuel.2015.06.077

Brown TM, Duan P, Savage PE (2010) Hydrothermal liquefaction and gasification of Nannochloropsis sp. Energy Fuels 24:3639-3646

Bwapwa JK, Anandraj A, Trois C (2017) Possibilities for conversion of microalgae oil into aviation fuel: a review. Renew Sustain Energy Rev 80:1345-1354. https://doi.org/10.1016/j.rser.2017.05.224

Cheng JJ, Timilsina GR (2011) Status and barriers of advanced biofuel technologies: a review. Renew Energy 36:3541-3549. https://doi. org/10.1016/j.renene.2011.04.031

Chisti Y (2016) Large-scale production of algal biomass: raceway ponds. In: Bux F, Chisti Y (eds) Algae biotechnology. Green energy and technology. Springer, Berlin, pp 21-40

Das P, Thaher MI, Hakim MAQMA, Al-Jabri HMSJ (2015) Sustainable production of toxin free marine microalgae biomass as fish feed in large scale open system in the Qatari desert. Bioresour Technol 192:97-104. https://doi.org/10.1016/j.biortech.2015.05.019

Das P, Thaher MI, Hakim MAQMA, Al-Jabri HMSJ, Alghasal GSHS (2016) A comparative study of the growth of Tetraselmis sp. in large scale fixed depth and decreasing depth raceway ponds. Bioresour Technol 216:114-120. https://doi.org/10.1016/j.biort ech.2016.05.058

Das P, Quadir MA, Chaudhary AK, Thaher MI, Khan S, Alghazal G, Al-Jabri H (2018) Outdoor continuous cultivation of self-settling marine cyanobacterium Chroococcidiopsis sp. Ind Biotechnol 14:45-53. https://doi.org/10.1089/ind.2017.0019

Das P, Thaher M, AbdulQuadir M, Khan S, Chaudhary A, Al-Jabri H (2019) Long-term semi-continuous cultivation of a halo-tolerant Tetraselmis sp. using recycled growth media. Bioresour Technol 276:35-41. https://doi.org/10.1016/j.biortech.2018.12.108

Duan P, Savage PE (2011) Hydrothermal liquefaction of a microalga with heterogeneous catalysts. Ind Eng Chem Res 50:52-61. https ://doi.org/10.1021/ie100758s

Faeth JL, Savage PE, Jarvis JM, Mckenna AM, Savage PE (2016) Characterization of products from fast and isothermal hydrothermal liquefaction of microalgae. AIChE J 62:815-828. https://doi. org/10.1002/aic.15147

Folch J, Lees M, Sloane Stanley GH (1957) A simple method for the isolation and purification of total lipides from animal tissues. $\mathbf{J}$ Biol Chem 226:497-509

Gai C, Zhang Y, Chen WT, Zhou Y, Schideman L, Zhang P, Tommaso G, Kuo CT, Dong Y (2015) Characterization of aqueous phase from the hydrothermal liquefaction of Chlorella pyrenoidosa. Bioresour Technol 184:328-335. https://doi.org/10.1016/j.biort ech.2014.10.118

González-Fernández C, Ballesteros M (2012) Microalgae autoflocculation: an alternative to high-energy consuming harvesting methods. J Appl Phycol 25:991-999. https://doi.org/10.1007/s1081 1-012-9957-3

Han Y, Hoekman SK, Cui Z, Jena U, Das P (2019) Hydrothermal liquefaction of marine microalgae biomass using co-solvents. Algal Res 38:101421. https://doi.org/10.1016/j.algal.2019.101421

He Z, Xu D, Wang S, Zhang H, Jing Z (2018) Catalytic upgrading of water-soluble biocrude from hydrothermal liquefaction of chlorella. Energy Fuels 32:1893-1899. https://doi.org/10.1021/acs. energyfuels.7b03823

Helsel ZR (1992) Energy and alternatives for fertilizer and pesticide use. In: Fluck R (ed) Energy in farm production, 6th edn. Elsevier, New York, pp 177-201

Hu Y, Feng S, Yuan Z, Xu CC, Bassi A (2017) Investigation of aqueous phase recycling for improving bio-crude oil yield in hydrothermal liquefaction of algae. Bioresour Technol 239:151-159. https://doi. org/10.1016/j.biortech.2017.05.033

Isa KM, Abdullah TAT, Ali UFM (2018) Hydrogen donor solvents in liquefaction of biomass: a review. Renew Sustain Energy Rev 81:1259-1268. https://doi.org/10.1016/j.rser.2017.04.006 
Jazrawi C, Biller P, He Y, Montoya A, Ross AB, Maschmeyer T, Haynes BS (2015) Two-stage hydrothermal liquefaction of a highprotein microalga. Algal Res 8:15-22. https://doi.org/10.1016/j. algal.2014.12.010

Leng L, Li J, Wen Z, Zhou W (2018) Use of microalgae to recycle nutrients in aqueous phase derived from hydrothermal liquefaction process. Bioresour Technol 256:529-542. https://doi. org/10.1016/j.biortech.2018.01.121

Lewis T, Nichols PD, McMeekin TA (2000) Evaluation of extraction methods for recovery of fatty acids from lipid-producing microheterotrophs. J Microbiol Methods 43:107-116. https://doi. org/10.1016/S0167-7012(00)00217-7

Li H, Liu Z, Zhang Y, Li B, Lu H, Duan N, Liu M, Zhu Z, Si B (2014) Conversion efficiency and oil quality of low-lipid high-protein and high-lipid low-protein microalgae via hydrothermal liquefaction. Bioresour Technol 154:322-329. https://doi.org/10.1016/j.biort ech.2013.12.074

López Barreiro D, Prins W, Ronsse F, Brilman W (2013) Hydrothermal liquefaction (HTL) of microalgae for biofuel production: state of the art review and future prospects. Biomass Bioenerg 53:113127. https://doi.org/10.1016/j.biombioe.2012.12.029

López Barreiro D, Bauer M, Hornung U, Posten C, Kruse A, Prins W (2015) Cultivation of microalgae with recovered nutrients after hydrothermal liquefaction. Algal Res 9:99-106. https://doi. org/10.1016/j.algal.2015.03.007

López CVG, García MDCC, Fernández FGA, Bustos CS, Chisti Y, Sevilla JMF (2010) Protein measurements of microalgal and cyanobacterial biomass. Bioresour Technol 101:7587-7591. https ://doi.org/10.1016/j.biortech.2010.04.077

Matsumoto M, Yoshida E, Takeyama H, Matsunaga T (2000) Floating cultivation of marine cyanobacteria using coal fly ash. Appl Biochem Biotechnol Part A Enzym Eng Biotechnol 84:51-57. https ://doi.org/10.1385/ABAB:84-86:1-9:51
Melis A (2009) Solar energy conversion efficiencies in photosynthesis: minimizing the chlorophyll antennae to maximize efficiency. Plant Sci 177:272-280. https://doi.org/10.1016/j.plantsci.2009.06.005

Minowa T, Yokoyama S, Kishimoto M, Okakura T (1995) Oil production from algal cells of Dunaliella-tertiolecta by direct thermochemical liquefaction. Fuel 74:1735-1738. https://doi. org/10.1016/0016-2361(95)80001-X

Patel B, Guo M, Chong C, Sarudin SHM, Hellgardt K (2016) Hydrothermal upgrading of algae paste: inorganics and recycling potential in the aqueous phase. Sci Total Environ 568:489-497. https:// doi.org/10.1016/j.scitotenv.2016.06.041

Peccia J, Haznedaroglu B, Gutierrez J, Zimmerman JB (2013) Nitrogen supply is an important driver of sustainable microalgae biofuel production. Trends Biotechnol 31:134-138. https://doi. org/10.1016/j.tibtech.2013.01.010

Ross AB, Biller P, Kubacki ML, Li H, Lea-Langton A, Jones JM (2010) Hydrothermal processing of microalgae using alkali and organic acids. Fuel 89:2234-2243. https://doi.org/10.1016/j. fuel.2010.01.025

Sharma KK, Garg S, Li Y, Malekizadeh A, Schenk PM (2014) Critical analysis of current microalgae dewatering techniques. Biofuels 4:397-407. https://doi.org/10.4155/bfs.13.25

Singh P, Kumari S, Guldhe A, Misra R, Rawat I, Bux F (2016) Trends and novel strategies for enhancing lipid accumulation and quality in microalgae. Renew Sustain Energy Rev 55:1-16. https://doi. org/10.1016/j.rser.2015.11.001

Speight JG (1999) The chemistry and technology of petroleum, 3rd edn. CRC Press, Boca Raton

Thao TY, Linh DTN, Si VC, Carter TW, Hill RT (2017) Isolation and selection of microalgal strains from natural water sources in Viet Nam with potential for edible oil production. Mar Drugs 15:194. https://doi.org/10.3390/md15070194 
Tiron O, Bumbac C, Manea E, Stefanescu M, Lazar MN (2017) Overcoming microalgae harvesting barrier by activated algae granules. Sci Rep 7:4646. https://doi.org/10.1038/s41598-017-05027-3

Uduman N, Qi Y, Danquah MK, Forde GM, Hoadley A (2010) Dewatering of microalgal cultures: a major bottleneck to algaebased fuels. J Renew Sustain Energy 2:012701. https://doi. org/10.1063/1.3294480

Venkatakrishnan VK, Degenstein JC, Smeltz AD, Delgass WN, Agrawal R, Ribeiro FH (2014) High-pressure fast-pyrolysis, fast-hydropyrolysis and catalytic hydrodeoxygenation of cellulose: production of liquid fuel from biomass. Green Chem 16:792-802. https://doi.org/10.1039/c3gc41558a

Yuan Y, Zhang H, Pan G (2016) Flocculation of cyanobacterial cells using coal fly ash modified chitosan. Water Res 97:11-18. https ://doi.org/10.1016/j.watres.2015.12.003

Zacher AH, Olarte MV, Santosa DM, Elliott DC, Jones SB (2014) A review and perspective of recent bio-oil hydrotreating research. Green Chem 16:491-515. https://doi.org/10.1039/c3gc41382a 